\title{
THE IMPACT OF ONLINE PRESENCE ON FIRM PERFORMANCE FOR U. S. SMALL BUSINESSES DURING THE 2007-2009 RECESSION
}

\author{
Emily Haag-Schmitt, Minnesota State University, Mankato, emily.schmitt@mnsu.edu \\ Queen E.Booker, Minnesota State University,Mankato,queen.booker@mnsu.edu
}

\begin{abstract}
This study examines the relationship between online presence and U.S. small firm performance during the 20072009 recessionary period. The paper specifically explores the impact of having a web presence on the return on assets of 570 U. S. small businesses. The analysis revealed that having a web presence positively and significantly improved the return on assets.
\end{abstract}

Keywords: SMEs, Electronic Commerce and Firm Performance

\section{INTRODUCTION}

According to the 2008 U. S. Census, $98 \%$ of employer firms had fewer than 100 employees. During the years 2006 to 2010 , small businesses looked for areas to gain a competitive advantage. A previous study analyzing the impact on training on small businesses revealed that small businesses that had a website were 14 percent more likely to be profitable than those that didn't. [12] In the age of the "user", prospective customers that only view a product or service online before going to the store, having an online presence is the only way to reach that target group. Other reasons to have an online presence include more accessibility, a greater audience, brand building, reviews, and overall easier marketing. [2]

This study argues that the association between an online presence and firm performance is magnified when the firm uses an online presence, specifically a website. The study uses data from 570 small businesses in the United States. Because of the wide range of definitions for small businesses, this study uses the definition of less than $\$ 50,000$ in assets and fewer than twenty full time equivalent employees. The study examines the return on assets covering the year 2008 which is the middle of the most recent U.S. recessionary period. Overall, there is strong evidence to show that the having a web presence has a positive effect on firm performance. [13]

\section{LITERATURE REVIEW}

Although there is no shortage of studies on small businesses and e-commerce, earlier studies have not examined how the having a web presence impacts firm performance but instead focuses on adoption factors and strategic advantages. For example, Grandon and Pearson [11] examined factors that determined strategic value and adoption of electronic commerce in small and medium sized enterprises (SME) and found three influential factors: operational support, managerial productivity, and strategic decision aids. They also identified four factors that influence electronic commerce adoption: organizational readiness, external pressure, perceived ease of use, and perceived usefulness. Wymer and Regan [17] examined the adoption and use of e-business and e-commerce information technology (EEIT) by small and medium enterprises (SMEs) and found 12 factors were significant in the adoption of e-commerce or online presences. Grandon et al [10] found that online presence was an effective strategy for rapid growth, especially by SMEs. They also found, though, that the adoption rate of e-commerce by SMEs was still undersized. Mehta and Shah [14] examined the growth of e-commerce and its advantages to small business firms. They suggested that small businesses could improve financial performance through the use of a web presence but did not actually explore that relationship but rather recommended steps to creating a successful online presence. Zhao et al [18] also studied U.S. small companies' business-to-consumer (B2C) e-commerce network systems. They found that Internet technologies have been changing the way business is conducted and U.S. small businesses are investing in such technologies and taking advantage of e-commerce to access global markets and compete with the large companies in their industries without the same levels of protection as their larger counterparts, e.g., firewalls and other security measures. 


\section{Issues in Information Systems \\ Volume 14, Issue 2, pp.210-216, 2013}

Similar to the research on small businesses and e-commerce, there is a plethora of research on small businesses and recessions. According to Chaston [6], small businesses have a higher level of bankruptcy than their larger counterparts during a recession. This is because, he purports, large firms have access to larger financial reserves or external borrowing whereas small firms tend to be reliant on bank borrowing and are less able to persuade banks to lend to them during an economic downturn.

This study builds on the current literature in that it offers quantitative analysis of the impact of having an online presence on a small business during a recessionary period which is a vulnerable period for all companies. The analysis shows that having a web presence can be valuable for small firms.

\section{RESEARCH METHODOLOGY}

This study was based on the data of 570 small businesses from across the United States collected from Chambers of Commerce, Small Business Associations, economic development organizations and Community Development Corporations. Because of the wide range of definitions for small businesses, this study uses the definition of less than $\$ 50,000$ in assets and fewer than twenty full time equivalent employees. The accounting measure of firm performance of the rate of profit after tax but before interest on total assets (namely, ROA) is used as the dependent variable. Chang and Choi [5] point out that this index is a more accurate measure of operating efficiency than other firm performance measures because the debt-equity ratio is usually high in small businesses. The majority of the control variables are from the Chu [8] study on family firms. Specifically the variables Assets, Diversification and Debt were used because they were significant to firm performance in the Chu analysis and would provide a basis for comparing the validity of the data used in the current study. Other significant control variables like Age and Number of Employees were not available for the study. Although it is known that the number of employees was twenty-five or less, the specific number of employees was not shared. In addition to the control variables from the Chu study, demographic dummy variables of Minority, Woman-Owned, Website, Facebook, Manufacturing, Southwest, Southeast, and Midwest were added. The independent variables are explained below.

\section{Firm assets (ASSETS)}

In industrial organization literature, firm assets reflect the existence of economies and diseconomies of scale and may form barriers to entry [1]. To avoid the problems of extreme values, firms with extremely low assets (e.g., close to zero) or extremely high assets of greater than $\$ 50,000$ were excluded from the study. The number of firms excluded based on outlier assets was seven.

\section{Diversification (DIVER)}

The diversification strategy of a firm is considered an important predictor of firm performance. Following Rumelt [15], a firm's diversification strategy is measured by the specialized ratio (SR) of a firm. The SR is defined as the proportion of a firm's revenue that is attributable to its largest group of businesses as of the year 2008. The larger the value of the SR, the more focused and less diversified is a firm. But rather than using the actual firm diversification value, DIVER was binary coded as 0 if the firm has focused and 1 if it was diversified. That is, if the firm diversification ratio was less than $75 \%$, it was coded as 1 .

\section{Debt in capital structure (DEBT)}

Debt in the capital structure is controlled because a firms' ownership structure may influence its capital structure [9]. This variable was measured by using the level of debt as of December 2008.

\section{Manufacturing (MANU)}

Chu used Industry because of possible profitability differences resulting from industrial affiliation. Given the small sample size and the wide range of self-reported classifications, firms with a manufacturing focus were coded as a 1 and all others were coded as 0 . [8] 


\section{Issues in Information Systems \\ Volume 14, Issue 2, pp.210-216, 2013}

\section{Diversity Variables}

The variables of Minority (MINOR), Woman-owned (WOMAN), Southwest (SW), Southeast (SE), Midwest (MW) were added to capture any influence the demographic variables could have on business performance. MINOR was coded as 1 if the business was majority owned by a minority, 0 if not. WOMAN was coded as 1 if majority owned by a woman, 0 if not. All of the geographic variables were coded as 1 if the firm was located in that area of the country and 0 if not. The location determined was based on which organization sent the data.

\section{Online presence variables}

Online presence variables were added to capture the effects, if any, of having an online presence in the form of a website or Facebook page. Having a website (WEB) was included because the introduction of new technology frequently presents unfamiliar problems as well as immense opportunities in organizations and can impact firm performance, the study is limited to companies with web presence prior to 2008 [12]. The variable is coded as 1 if the firm had a web presence prior to 2008 and 0 if not. No attempt was made to distinguish between an informational web presence only or if the site was a fully functioning e-commerce site.

Facebook Presence (FB) Similar to the argument used for WEB, the firms used in this study are limited to those with no Facebook presence or a Facebook presence prior to 2008. If the firm has a Facebook presence prior to 2008, the variable is coded as 1 and 0 if not.

Empirical evidence from prior studies suggests that there could be is a positive relationship between a web presence and firm performance. Saeed et al [16] wrote that the advent of electronic commerce induced many organizations to develop a Web presence and exploit the opportunities offered by the Internet. But because websites are easy to imitate through instant access to information on competitor's offerings, it is not clear how to build a sustainable competitive advantage. Their results suggested that large firms with high electronic commerce competence exhibit superior performance and that customer value generated through Web site functionality partially mediates this relationship. In addition, the results showed that companies can enhance short-term performance.

This study follows the Saeed perspective and extends it for small businesses, using website and Facebook presence as the variables. The research hypotheses to be tested are as follows:

$\mathrm{H}_{1}$ : Having an established website is significantly and positively associated with small firm performance during a recession.

$\mathrm{H}_{2}$ : Having an established Facebook presence is significantly and positively associated with small firm performance during a recession.

Prior to testing the hypotheses, the data was analyzed using Cronbach's alpha to ensure consistency since the data came from multiple sources. Descriptive statistics were run to ensure the overall dataset was consistent with the U.S. Small Business Data for 2008. To test the hypotheses, two regression models were developed. The first model is a confirmatory model to ensure that the control variables from prior studies to ensure that the data provided is consistent with prior research results. The second regression model adds the Online Presence variables to the model. The models were developed using the stepwise approach.

\section{RESULTS}

Cronbach's alpha was run on the combined datasets. The value was 0.73 which is acceptable for combining the data. Table 1 reports the descriptive statistics for the selected firms. Table 2 reports the correlations among variables. Table 3 shows the results of the regression analysis with ROA as the dependent variables without control variables WEB and FB. Table 4 shows the results of the regression analysis with all the control variables. 


\section{Issues in Information Systems}

Volume 14, Issue 2, pp.210-216, 2013

The descriptive statistics show that $16 \%$ of the firms studied were owned by women and $17 \%$ were owned by minorities. The study did not distinguish between domestic U.S. minorities and immigrant minorities. The data was fairly evenly received from across United States geographic regions with $26 \%$ from the Midwest, $28 \%$ from the Southwest, $23 \%$ from the Southeast and 23\% from the North. There is a probable bias in the data in that the analysis is dependent on data sent from outside institutions and not the firms themselves. There is no opportunity to validate the data received and maintain the anonymity required for the data collected

Table 1. Descriptive Statistics

\begin{tabular}{|l|l|l|}
\hline Variables & Mean & S.D. \\
\hline ROA & 5.37 & 1.77 \\
\hline WOMAN & 0.16 & 0.36 \\
\hline MINOR & 0.17 & 0.37 \\
\hline MW & 0.26 & 0.44 \\
\hline SW & 0.28 & 0.45 \\
\hline SE & 0.23 & 0.42 \\
\hline WEB & 0.64 & 0.48 \\
\hline FB & 0.14 & 0.35 \\
\hline ASSETS & 22.81 & 4.73 \\
\hline DEBT & 27.74 & 6.98 \\
\hline MANU & 0.30 & 0.46 \\
\hline DIVER & 0.41 & 0.49 \\
\hline
\end{tabular}

Table 2. Correlations among variables ( $\mathrm{n}=570$ small firms).

\begin{tabular}{|c|c|c|c|c|c|c|c|c|c|c|c|}
\hline & WOMAN & MINOR & MW & SW & $\overline{\text { SE }}$ & WEB & FB & ASSETS & DEBT & MANU & DIVER \\
\hline$R O A$ & $(0.01)$ & $(0.05)$ & 0.06 & $(0.14)$ & 0.07 & 0.11 & 0.05 & 0.48 & 0.08 & 0.09 & $(0.16)$ \\
\hline WOMAN & 1.00 & 0.36 & $(0.11)$ & 0.11 & 0.03 & $(0.02)$ & $(0.02)$ & 0.01 & $(0.03)$ & $(0.04)$ & 0.01 \\
\hline MINOR & & 1.00 & $(0.02)$ & 0.14 & $(0.10)$ & $(0.06)$ & $(0.02)$ & 0.05 & 0.09 & $(0.03)$ & 0.01 \\
\hline$M W$ & & & 1.00 & $(0.36)$ & $(0.33)$ & 0.05 & 0.06 & $(0.02)$ & 0.02 & 0.03 & $(0.05)$ \\
\hline$S W$ & & & & 1.00 & $(0.34)$ & $(0.09)$ & 0.05 & $(0.11)$ & $(0.07)$ & $(0.09)$ & $(0.01)$ \\
\hline$\overline{S E}$ & & & & & 1.00 & 0.01 & $(0.10)$ & 0.09 & $(0.01)$ & 0.02 & 0.03 \\
\hline$W E B$ & & & & & & 1.00 & $(0.04)$ & 0.02 & $(0.01)$ & $(0.17)$ & $(0.08)$ \\
\hline$F B$ & & & & & & & 1.00 & 0.04 & 0.06 & 0.03 & 0.01 \\
\hline ASSETS & & & & & & & & 1.00 & 0.56 & 0.28 & 0.06 \\
\hline$D E B T$ & & & & & & & & & 1.00 & 0.21 & 0.19 \\
\hline$M A N U$ & & & & & & & & & & 1.00 & 0.23 \\
\hline
\end{tabular}

The correlation table in Table 2 provides information that warrants further study. Southwest (SW), Woman-owned (WOMAN) and Minority owned (MINOR) are all negatively correlated with having a website presence (WEB) as are Debt (DEBT), Manufacturing (MANU) and Diversification (DIVER) although firm performance (ROA) is only negatively correlated with WOMAN, MINOR, and DIVER. The result of the diversification and ROA is supported in the Chu study. While no study was found to support the negative relationship with WOMAN and MINOR, and 
ROA, the Chow and Dunkelberg [7] study suggested that during recessionary periods such firms are less likely to find debt financing to bridge performance gaps.

Table 3. Regression Model Analysis without WEB and FB control variables

\begin{tabular}{|c|c|c|c|}
\hline & Coefficients & $\begin{array}{l}\text { Standard } \\
\text { Error }\end{array}$ & t Stat \\
\hline Constant & 2.05 & 0.35 & 5.86 \\
\hline WOMAN & 0.05 & 0.18 & 0.29 \\
\hline MINOR & $(0.23)$ & 0.18 & $(1.26)$ \\
\hline MW & 0.17 & 0.18 & 0.97 \\
\hline SW & $(0.30)^{*}$ & 0.18 & $(1.72)$ \\
\hline $\mathbf{S E}$ & 0.00 & 0.18 & 0.01 \\
\hline ASSETS & $0.23 * * *$ & 0.02 & 14.47 \\
\hline DEBT & $(0.06)^{* * *}$ & 0.01 & $(5.67)$ \\
\hline MANU & $(0.02)$ & 0.14 & $(0.15)$ \\
\hline DIVER & $(0.56)^{* * *}$ & 0.13 & $(4.24)$ \\
\hline \multicolumn{4}{|c|}{ Adjusted R-squared: $0.31 * * *$} \\
\hline \multicolumn{4}{|c|}{ 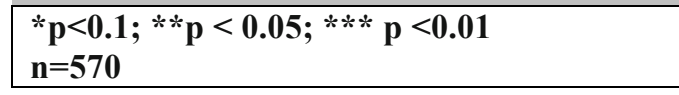 } \\
\hline
\end{tabular}

The regression model in Table 3 has all the control variables except the hypothesis variables of WEB and FB included in the equation. The selected variables only explain about $31 \%$ of the return on assets which mean the model itself is not reliable for fully explaining the independent variable. However, certain variables emerged as significant including diversification, debt and assets. This outcome is consistent with the results found by Chu. Southwest was also significant but at the $\mathrm{p}<0.1$ level.

Table 4. Full Model Regression Analysis Results

\begin{tabular}{|l|l|l|l|}
\hline & Coefficients & $\begin{array}{l}\text { Standard } \\
\text { Error }\end{array}$ & t Stat \\
\hline Constant & 1.88 & 0.36 & 5.26 \\
\hline WOMAN & 0.05 & 0.18 & 0.29 \\
\hline MINOR & $(0.20)$ & 0.18 & $(1.11)$ \\
\hline MW & 0.16 & 0.18 & 0.90 \\
\hline SW & $(0.28)$ & 0.18 & $(1.62)$ \\
\hline SE & 0.02 & 0.18 & 0.12 \\
\hline WEB & $0.26^{* *}$ & 0.13 & 2.02 \\
\hline FB & 0.20 & 0.18 & 1.12 \\
\hline ASSETS & $0.23^{* * *}$ & 0.02 & 14.34 \\
\hline DEBT & $(.0 .06)^{* * *}$ & 0.01 & $(5.71)$ \\
\hline MANU & 0.03 & 0.14 & 0.18 \\
\hline
\end{tabular}




\begin{tabular}{|c|c|c|c|}
\hline DIVER & $(0.54)^{* * *}$ & 0.13 & (4.17) \\
\hline \multicolumn{4}{|c|}{ Adjusted R-squared: $0.32 * * *$} \\
\hline \multicolumn{4}{|c|}{ 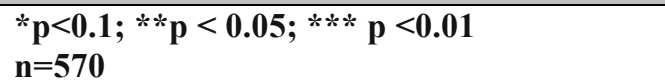 } \\
\hline
\end{tabular}

Table 4 shows the full model with all the control variables. The model only slightly improves with the addition of the online presence from 0.31 to 0.32 . In the full model, WEB is significant at the $p<0.05$ level but FB is not significant at all. Other significant variables are DIVER, DEBT and ASSETS which means all of the variables except SW from the base model remained significant.

To test Hypotheses 1 and 2, the regression analyses results were used to determine whether or not to accept the hypotheses. Recall our hypotheses:

Hypothesis 1 Having an established website is significantly and positively associated with small firm performance during a recession.

Hypothesis 2 Having an established Facebook presence is significantly and positively associated with small firm performance during a recession.

Based on the regression results, because WEB was significant at $\mathrm{p}<.0 .05$ hypothesis 1 can be accepted since WEB is both significant and positive. FB was positive but not significant. Therefore hypothesis 2 must be rejected.

This study goes one step further in examining the data by splitting it by geographic region. Table 5 shows the average ROA based on location and web presence shows that the ROA is higher for all geographic regions. Table 6 shows the average ROA based on location and Facebook presence.

Results of the analyses suggest that there was no particular relationship between geographic region and the online presence variables. Thus additional data and an examination of the type of website presence (web marketing only versus full e-commerce) and activity of Facebook presence (coupons, marketing, number of friends) are necessary to fully understand the impact of the online presence on the firm performance. However, this preliminary study does suggest that there was value in having some web presence in 2008 for small businesses in the United States.

Table 5. Comparison of ROA of firm by geographic region and web presence

\begin{tabular}{|l|l|l|l|}
\hline & Non Web Presence & Web Presence & Difference \\
\hline North & 5.45 & 5.49 & 0.04 \\
\hline Southeast & 5.19 & 5.82 & 0.63 \\
\hline Southwest & 4.74 & 5.12 & 0.38 \\
\hline Midwest & 5.29 & 5.66 & 0.37 \\
\hline
\end{tabular}

Table 6. Comparison of ROA of firms by geographic region and Facebook Presence

\begin{tabular}{|l|l|l|l|}
\hline & Non Facebook Presence & Facebook Presence & Difference \\
\hline North & 5.34 & 6.17 & 0.83 \\
\hline Southeast & 5.63 & 5.28 & -0.35 \\
\hline Southwest & 4.90 & 5.22 & 0.32 \\
\hline Midwest & 5.52 & 5.64 & 0.11 \\
\hline
\end{tabular}




\section{Issues in Information Systems}

Volume 14, Issue 2, pp.210-216, 2013

\section{CONCLUSIONS}

This study goes beyond existing studies by examining the possible effects on firm performance of an online presence for small businesses during a recession. This preliminary study suggests that having a website is a significant factor along with assets, debt, and limited diversification contributed to higher firm performance. The findings of this study support the results of the validity of debt and asset level for firm performance and shed some supportive results of the effectiveness and value added of web presence. But this research has several limitations. The data is limited to 570 firms in the United States and data provided by third party sources. Other variables that may influence web presence such as type of ownership (e.g., franchise versus family owned) which could also affect the web presence results were not included and should be examined. Tax structures in different states could have impacts as well because the ROA was based on post tax profits. Thus, the list of the factors identified in this study is not meant to be an exhaustive one. This study suggests that these variables could explain a share of the variance in the web presence-performance relationship. Next steps include a deeper analysis into the type of firm, analysis over multiple periods rather than just one year, and other factors suggested in the literature that affect firm performance such as ownership type, age of the firm and the specific type of industry.

\section{REFERENCES}

1. Bain, J. S. (1968). Industrial organization. New York: Wiley.

2. Blasingame, J. (2011) The New Class of Small Business Influencers. Forbes Magazine

3. Cavery, B. (1998). Availability of credit to family businesses. Small Business Economics, 11(1): 75-86.

4. Chandler, A. D. (1990). Scale and scope: The dynamics of industrial capitalism. New York: Free.

5. Chang, S. J., \& Choi, U. (1988). Strategy, structure and performance of Korean business group: A transaction cost approach. Journal of Industrial Economics, 37(2): 141-158.

6. Chaston, I. (2009). Small firms and entrepreneurship. London, UK: Sage.

7. Chow, M. \& Dunkelberg, W. (2011) The Small Business Sector in Recovery. Business Economics, 46: 214228.

8. Chu, W. (2009) Family Ownership and firm performance: Influence of family management, family control and firm size. Asia-Pacific Journal of Management, 28. 833-851.

9. Demsetz, H., \& Lehn, K. (1985). The structure of corporate ownership: Causes and consequences. Journal of Political Economy, 93(6): 1155-1177.

10. Grandón, E.E, Nasco, S. A., \& Mykytyn Jr., P. P. (2011) Comparing theories to explain e-commerce adoption, Journal of Business Research, 64 (3),292-298

11. Grandon, E. \& Pearson,M. J. (2004) Electronic commerce adoption: an empirical study of small and medium US businesses, Information \& Management, 42 (1): 197-216

12. Haag, E. (2012), Impacts and Results of Cuts in Training and Development budgets on local small businesses. Journal of Undergraduate Research, 12

13. Kang, S., (1998), Information Technology Acceptance: Evolving with the Changes in the Network Environment, Proceeding of IEEE 31 St Hawaii international conference on system science, Hawaii

14. Meehta, K. T. \& Shah, V. (2001) E-Commerce: The Next Global Frontier For Small Businesses, Journal Of Applied Business Research, 17 (1)

15. Rumelt, R. P. (1974). Strategy, structure, and economic performance. Boston: Harvard Business School. Scherer, F. M. 1980. Industrial market structure and economic performance, 2nd ed. Chicago: Rand McNally College.

16. Saeed, K. A., Grover, V., \& Hwang, Y. (2005) The Relationship of E-Commerce Competence to Customer Value and Firm Performance: An Empirical Investigation. Journal of Management Information Systems, 22 (1). 223-256

17. Wymer, S., \& Regan, E. A. (2011). Influential Factors in the Adoption and Use of E-Business and E-Commerce Information Technology (EEIT) by Small \& Medium Businesses. Journal of Electronic Commerce in Organizations (JECO), 9(1): 56-82.

18. Zhao, J. J., Truell, A. D., Alexander, M. W., and Woosley, S. A. (2011) A Vulnerability Assessment of the U.S. Small Business B2C E-Commerce Network Systems. Delta Pi Epsilon Journal, 53 (1).42-52. 